\title{
Effect of fetal sex on labour and delivery: retrospective review
}

\author{
Maeve A Eogan, Michael P Geary, Michael P O'Connell, Declan P Keane
}

The association of fetal sex with pregnancy induced hypertension and pre-eclampsia, the interaction between sex and risk factors for fetal growth restriction, and the increased likelihood of second stage arrest with male sex have all been studied. ${ }^{1-3}$ However, a Medline search (1966 to August 2002) using the search terms fetal gender, fetal sex, labour, delivery, and childbirth found no studies on the effect of fetal sex itself on labour outcomes and events. We set out to determine the effect of fetal sex on birth weight, duration of labour, mode of delivery, and birth outcome.

\section{Subjects, methods, and results}

In the National Maternity Hospital, Dublin, where the study took place, labour and delivery are actively managed according to a standard protocol. ${ }^{4}$ We obtained data from the delivery ward database for the period 1 January 1997 to 31 December 2000 on all primigravid mothers who had a singleton, cephalic fetus and who spontaneously went into labour at term. We confined the analysis to this group to avoid the confounding effects of induced labour and previous parity. We excluded stillbirths, neonatal deaths, and infants with congenital anomalies. We used a $\chi^{2}$ test with Yates's correction $(\mathrm{P}$ values were considered significant at the level of $<0.01)$. Among the variables studied were gestation, need for antibiotics, need for oxytocin augmentation, colour of liquor, need for fetal blood sampling, use of epidural analgesia, duration of labour, and mode of delivery, as well as birth weight.

In the study period 4070 male and 4005 female infants fulfilled the inclusion criteria. Male infants were significantly more likely to require oxytocin augmentation, fetal blood sampling, and instrumental vaginal delivery or caesarean section (table). Female infants were more likely to have meconium stained liquor. There was no statistically significant difference between the sexes in gestation, requirement for antibiotics in labour, or the number of infants with no liquor in labour.

Multiple regression analysis, with adjustment for confounding factors that are known to affect labour and delivery outcome (such as birth weight, duration of labour, and use of epidural analgesia), showed a strong association between fetal sex and birth weight, duration of labour, and mode of delivery. However, mode of delivery was not associated with birth weight.

\section{Comment}

Primigravid women who go into labour spontaneously and at term are more likely to encounter complications during labour and delivery when the infant is a boy. We found no biases in the data studied that could account for the difference; specifically, demographic details of the mothers were similar. Furthermore, the possible confounding effects of parity and induction of labour were removed by confining this analysis to spontaneously labouring primigravid women.
Effect of sex of fetus on labour outcomes and events. Values are numbers (\%) of infants unless stated otherwise

\begin{tabular}{lccc} 
Outcome or event & Male infants & Female infants & $\begin{array}{c}\text { P value for } \\
\text { difference }\end{array}$ \\
\hline Total & 4070 & 4005 & \\
\hline Gestation (weeks) & 39.8 & 39.8 & NS \\
\hline Liquor: & $2648(65.1)$ & $2498(62.4)$ & NS \\
\hline Clear & $784(19.2)$ & $917(22.9)$ & $<0.0001$ \\
\hline Meconium & $241(5.9)$ & $239(5.9)$ & NS \\
\hline None & $397(9.8)$ & $351(8.8)$ & NS \\
\hline Blood stained & $370(9.1)$ & $374(9.3)$ & NS \\
\hline Antibiotics given during labour & $2435(59.8)$ & $2279(56.9)$ & 0.008 \\
\hline Oxytocin augmentation & $2829(69.5)$ & $2667(66.6)$ & 0.005 \\
\hline Epidural analgesia & $792(19.5)$ & $662(16.5)$ & 0.0007 \\
\hline Fetal blood sample taken & $376(193)$ & $352(296)$ & $<0.001$ \\
\hline Mean (SD) duration of labour (minutes) & & & \\
\hline Mode of delivery: & $2896(71.2)$ & $3064(76.5)$ & $<0.0001$ \\
\hline Spontaneous vertex delivery & $249(6.1)$ & $170(4.2)$ & 0.0002 \\
\hline Lower segment caesarean section & $324(8.0)$ & $258(6.4)$ & 0.009 \\
\hline Forceps & $601(14.8)$ & $513(12.8)$ & 0.01 \\
\hline Ventouse & $3574(457)$ & $3453(435)$ & $<0.001$ \\
\hline Mean (SD) birth weight (g) & & & \\
\hline Destination: & $3911(96.1)$ & $3882(96.9)$ & NS \\
\hline Ward & $159(3.9)$ & $123(3.1)$ & NS \\
\hline Special care baby unit & & \\
\hline
\end{tabular}

The reason for the impact of fetal sex on birth outcome is unclear. Male infants have a significantly larger head size than female infants, and this may contribute to the duration of labour and the higher incidence of operative delivery. ${ }^{5}$ Although we adjusted for birth weight of the infants, we did not consider data on head circumference. However, this factor would not fully explain the sex difference, as duration of labour alone would not account for the increased incidence of suspected fetal distress in males (as evidenced by their increased need for fetal blood sampling). What this study does show is that when we say "it must be a boy" as a humorous explanation of complications of labour and delivery we are scientifically more correct than previously supposed.

Contributors: MAE had the original idea for the study. MAE, DPK, and MPO'C designed the study. MAE, MPO'C, and MPG managed the data collection and entry. MPO'C and MPG analysed the data. All authors contributed to interpretation of results and to the writing of the paper. MAE will act as guarantor. Funding: None.

Competing interests: None declared.

1 Makhseed M, Musini VM, Ahmed MA. Association of fetal gender with pregnancy induced hypertension and pre-eclampsia. Int J Gynaecol Obstet pregnancy ind

2 Spinillo A, Capuzzo E, Nicola S, Colonna L, Iasci A, Zara C. Interaction between fetal gender and risk factors for fetal growth retardation. $\mathrm{Am} \mathrm{J}$ Obstet Gynecol 1994;171:1273-7.

3 Feinstein U, Sheiner E, Levy A, Hallak M, Mazor M. Risk factors for arrest of descent during the second stage of labour. Int J Gynaecol Obstet 2002;77:7-14.

4 O'Driscoll K, Meagher D, Boylan P. Active management of labour. London: Mosby, 1993.

5 Hindmarsh PC, Geary MP, Rodeck CH, Kingdom JC, Cole TJ. Intrauterine growth and its relationship to size and shape at birth. Pediatr Res 2002;52:263-8.

(Accepted 4 October 2002)
National Maternity Hospital, Holles St, Dublin 2, Republic of Ireland

Maeve A Eogan specialist registrar Michael P Geary assistant master

Michael P

O'Connell assistant master Declan P Keane master

Correspondence to: M A Eogan maeveeogan@ eircom.net

BMJ 2003;326:137 